\title{
Examining projection bias in experimental auctions: the role of hunger and immediate gratification
}

\author{
Teresa Briz ${ }^{1 *}$, Andreas C. Drichoutis ${ }^{2}$ and Lisa House ${ }^{3}$
}

\author{
* Correspondence: \\ teresa.briz@upm.es \\ ${ }^{1}$ Department of Agricultural \\ Economics, E.T.S. Ingenieros \\ Agrónomos Universidad Politécnica \\ de Madrid, 28040 Madrid, Spain \\ Full list of author information is \\ available at the end of the article
}

\begin{abstract}
The relevance of projection bias in decision making processes has been widely studied, but not specifically in experimental auctions. We study the role of projection bias in experimental auctions by examining the bidding behavior of hungry and non-hungry subjects on food products delivered either immediately after the auction or in 1 week's time. Results indicate that the difference in bids between a hot state (hunger) and a cold state (satiation) almost doubles when subjects have to predict their future tastes versus when they bid for a product intended for immediate consumption. More specifically, when subjects have to predict their future willingness to pay from their current tastes, they tend to over-predict their hunger and under-predict satiation.
\end{abstract}

Keywords: Experimental auction; Willingness to pay; Projection bias; Hunger

\section{Background}

Microeconomic theory posits that consumers accurately predict their future utility when solving their intertemporal optimization problems. However, accurately predicting future tastes requires that consumers understand both the direction and magnitude of how their tastes might change (Loewenstein et al., 2003). Unfortunately, consumers do not always accurately predict these changes in their tastes and preferences. Loewenstein et al. (2003) coined the term "projection bias" to describe the general bias that has been documented in relation to the prediction of future tastes.

One type of projection bias that occurs is when individuals fail to adequately predict future conditions that influence their current decisions. For example, customers ordering catalog clothes are overly influenced by the current weather (e.g., warm clothes orders jump significantly in cold weather and are then returned afterwards) (Conlin et al., 2007); the sales of expensive and lasting goods, such as cars and houses, are also affected by the weather conditions at the time of the decision (Busse et al. 2012); people aroused by hunger, sex, or anger mispredict how they would act in a "calmer" state and, similarly, when they are in a cool state, mispredict the influence of arousal (Loewenstein et al., 2003). In the field of medical science, patients who are in a state of fear or anxiety due to receipt of an adverse test result might need to make important treatment decisions with consequences that will apply after they have calmed down (Loewenstein, 2005). In all of these examples, if the decisions apply to the present 
situation, then there should be no (projection) bias; whereas decisions applying to later times but made under current conditions can be subject to projection bias. In other words, people are likely to misjudge their future conditions and make decisions that differ from what they would if the future condition was equal to the current condition.

Projection bias is evident in the food domain as well. Hungry shoppers tend to buy different food items than non-hungry shoppers and their consumption pattern resembles that of people who expect to remain permanently famished (Mela et al., 1997; Nisbett and Kanouse, 1968). Hence, willingness to pay (WTP) for food products of hungry and non-hungry shoppers could vary as well depending on their hunger state. A higher WTP has been shown when participants are more likely to be hungry or focused in the purchase of food (Demont et al., 2012). However, Gilbert et al. (2002) found that if hungry shoppers were given a small piece of food (e.g., a muffin) right before entering a food market, they were able to limit their shopping to the initial items on a shopping list (Gilbert et al., 2002). This documented bias is particularly important since the decision results may then carry on into subsequent periods. In this case, projection bias can be closely related to the lasting consequences of current decisions. For example, Read and van Leeuwen (1998) presented office workers a choice of healthy and non-healthy snacks (fruit vs. candy bars) to be delivered in a week's time, either at a time when they were expected to be hungry or full. The workers chose the candy bar when they were expected to be hungry (since snacks are considered more satiating; see Jack et al., 1997). In addition, if they were hungry at the moment of the buying decision, they were also more likely to choose the candy bar for any other subsequent occasion they were presented a choice.

Although the concept of projection bias as coined by Loewenstein et al. (2003) has been studied in the literature, there are no known papers dealing with projection bias in experimental auction settings where the objective is to examine people's valuation for specific products (i.e., eliciting homegrown values). This is in part expected, given that most experiments auction either perishable food products (intended for immediate or proximate consumption) or products for immediate purchase. But what if consumers have to project their current preferences on a future date due to a variety of reasons such as current satiation? How would that reflect on their valuation for a product and thus their current decision to bid for the product? When studying willingness to pay for food, in experimental auctions, consumption is typically immediate or proximate, indicating there would be no projection bias. An imposed consumption requirement (as in Fox, 1995; Shogren et al. 2001) permits experimental control and ensures participants consider more seriously their bidding decisions. Nevertheless, many other interesting studies dealing with varied food items (steaks, tortilla chips and salsa, candy bar, GMO products, rice, organic olive oil, etc.) and experimental auctions do not involve immediate consumption (Corrigan and Rousu, 2006a, 2006b; Depositario et al., 2009; Lusk et al., 2004a, 2004b; Soler et al., 2002).

Consumers are often faced with making a current decision for future consumption (i.e. purchasing groceries for a week's time period), and their failure to account for projection bias could then render biased decisions, i.e. basing their decisions on a hot state with the potential to regret later. In our experiments, the difference in bids between a hot state and a cold state almost doubles when subjects have to project their tastes in 1 week's time.

In this article, we attempt to shed some light on the potential of the existence of projection bias in experimental auctions by auctioning food products that are intended for delivery and consumption either in the present or at a future date. We propose two central 
hypotheses that serve as the basis for the subsequent discussion: 1) depending on the various states subjects are in (hungry or not, in our case), they will project their needs differently which will be reflected in their bids for a product delivered in the future; and 2) irrespective of their hunger status, subjects who expect to receive the food product at a future date will have lower valuations for the product given the lack of ability to judge their future tastes differently from the ones in the current situation. We test these hypotheses by conducting experimental auctions at different points in time during the day (to vary hunger levels) with the food product to be received at varying times (immediately after the auction or with a time lag). Additionally, when the product is being given in the future, subjects will have to pay either in advance (at the end of the auction) or at the moment of receipt of the product. The next section presents our experimental design and procedures. The econometric analysis and results follow. We conclude with some final thoughts in the last section.

\section{Methods}

To explore the effect of projection bias on product valuation, we designed an experiment to test whether mistaken inferences about whether current states will also be felt at future points in time would appear as an effect on a subject's WTP for a perishable food product. First, we exogenously varied hunger levels by having subjects bid for a perishable food product (which was expected to be consumed right after the auction and not saved for the future) in two different times of the day when we expected subjects to be hungry or satiated. Half of the subjects participated in an auction immediately before lunch time and half of the subjects participated in an auction immediately after lunch time. Since we could not control whether a subject would be hungry or full at any given time (e.g., a subject may have decided to skip lunch or, conversely, to eat a satiating snack before lunch time), we also asked subjects about the time since their last meal (Fig. 1).

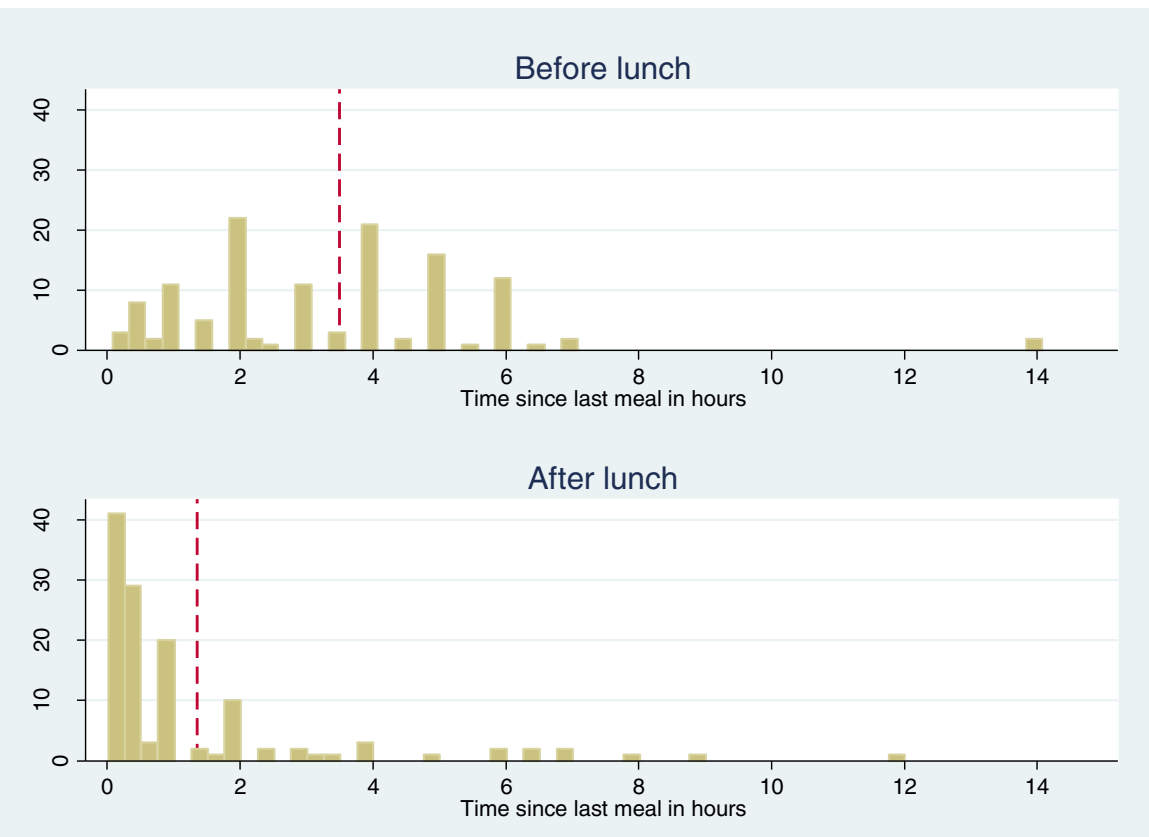

Fig. 1 Histograms of time since last meal by time of the day session (dashed lines depict means) 
Comparing bids from the before-lunch and after-lunch sessions allows us to get an estimate of the effect of hunger on WTP. ${ }^{1}$ To test if hunger levels would have an effect (if any) on projection bias, in half of the treatments we promised delivery of the sandwich with a time lag (i.e., exactly 1 week later) in addition to exogenously varying hunger levels. A comparison of the before-and after-lunch WTP values in treatments where delivery of the product is in the future and in treatments where delivery of the product is right after the auction gives us an indication on the mediation of hunger on projection bias (if any). Our experiment was conducted in Madrid, Spain.

Our between-subjects design involved six treatments in 12 sessions. To control for hunger levels we conducted sessions at two different times of the day: before lunch (6 sessions) and after lunch (6 sessions). In Spain, lunch is the main meal and unlikely to be skipped, and following local habits for lunch, the schedules set for the experiments were at $1 \mathrm{pm}$ (before lunch) and at $3 \mathrm{pm}$ (after lunch). For obvious reasons, we expected more hungry participants in the first case and less hungry participants in the second case. As mentioned previously, although the timing of the sessions were scheduled so as to have "hungry" and "satiated" participants, subjects were also asked questions pertaining to the time since their last meal. In an attempt to have similar meal situations for all participants, the experiments were carried out in the middle of the week (Tuesdays, Wednesdays, and Thursdays), to avoid potential effects of "weekend leftovers" that participants may bring on Mondays or special weekend plans on Fridays.

We also varied the time of delivery of the product to the highest bidders. In some sessions subjects received the food product immediately after the session (as is standard practice in auctions), while in other sessions delivery of the product occurred exactly 1 week later at the same time of the day. ${ }^{2}$ Highest bidders in the delayed delivery sessions received a coupon with which they could redeem their product from the experimenters. Subjects were assured that the products would be available when they redeemed their coupons the following week. To test the effect of imposing a commitment cost on subjects' valuation, half of the sessions that promised delivery of the good 1 week later required up-front payment for the good while the other half of the sessions required payment of the good upon delivery. The experimental design used in the study is depicted in Table 1. Overall, this

Table 1 Experimental design and number of subjects participating per session

\begin{tabular}{|c|c|c|c|c|}
\hline \multirow{2}{*}{$\frac{\text { Time of the day }}{\text { Before lunch }}$} & \multicolumn{3}{|c|}{ Time of delivery of the sandwich } & \multirow{2}{*}{$\frac{\text { Tota }}{66}$} \\
\hline & \multirow{2}{*}{\multicolumn{2}{|c|}{ After the auction }} & 66 & \\
\hline & & & 3 sessions & \\
\hline & \multirow[t]{4}{*}{1 week after the auction } & \multirow{2}{*}{$\begin{array}{l}\text { Subjects had to pay immediately } \\
\text { after the auction }\end{array}$} & 40 & 62 \\
\hline & & & 2 sessions & \\
\hline & & \multirow{2}{*}{$\begin{array}{l}\text { Subjects had to pay } 1 \text { week after } \\
\text { the auction }\end{array}$} & 22 & \\
\hline & & & 1 session & \\
\hline \multirow[t]{6}{*}{ After lunch } & \multirow[t]{2}{*}{ After the auction } & & 64 & 64 \\
\hline & & & 3 sessions & \\
\hline & \multirow[t]{4}{*}{1 week after the auction } & \multirow{2}{*}{$\begin{array}{l}\text { Subjects had to pay immediately } \\
\text { after the auction }\end{array}$} & 20 & 60 \\
\hline & & & 1 session & \\
\hline & & \multirow{2}{*}{$\begin{array}{l}\text { Subjects had to pay } 1 \text { week after } \\
\text { the auction }\end{array}$} & 40 & \\
\hline & & & 2 sessions & \\
\hline \multicolumn{3}{|l|}{ Total } & & 252 \\
\hline
\end{tabular}


study employs a 3 (future with immediate payment vs. future with delayed payment vs. present consumption) $\times 2$ (before vs. after lunch) between subjects design. We treat time since last meal a covariate throughout the analysis.

Two hundred and fifty-two subjects participated in the lab experiment. Each subject participated in only one session. The size of the groups varied from 18 to 22 subjects per session and each session lasted about $1 \mathrm{~h}$. Subjects were recruited through an announcement placed at the Universidad Politécnica de Madrid (Spain). Although the announcement was open to everybody, the great majority of participants were students from the university. Each participant was randomly assigned to a session for the study.

The product of the auction was carefully chosen so that it would be a typical and widely accepted lunch product and perfectly known to subjects. Consequently, a ham and cheese sandwich was used in the auction. We chose a perishable food product so that subjects knew they were bidding for a product intended for immediate consumption, and consequently to make subjects' current hunger status relevant to bidding behavior. To elicit subjects' WTP, a fourth-price Vickrey auction was employed. Considering the size of the session groups and the likelihood of disengaging some of the participants due to the small number of winners, the fourth-price auction was regarded as a compromise between a second-price auction and a random nthprice auction for engaging off-margin bidders. Shogren et al. (2001) found that the second-price auction worked better for on-margin bidders while the random nthprice auction worked better for off-margin bidders. Since the rules of the auction are somewhat complicated, we spent a significant amount of time educating and training the subjects about the auction mechanism. After arriving at the room reserved for the sessions, subjects were randomly seated. They were given an acceptance form and they received 10 euros $(€)$ for taking part in the study, which they could use in the actual auction. A training phase with the auction mechanism was then conducted where the experimenter thoroughly explained how a fourth-price auction works. Subjects then took a short test regarding the procedure. The monitor explained the correct answers afterwards and made sure that all subjects completely understood the auction mechanism. Additionally, we conducted a "practice auction" to further show subjects how the auction works. In this practice auction, subjects had to bid in three real practice rounds for another product. The monitor emphasized that these rounds were real; that one binding round would be randomly chosen at the end of these rounds and that the highest bidders would actually have to pay for the products. The practice auction was identical for all sessions and was not part of the treatment design. The only purpose was to demonstrate to subjects how a fourth-price auction works. The experimental treatments were only applied to the ham and cheese sandwich. All transactions were completed at the end of the experiment. Subjects who participated in the "future delivery of the sandwich" treatments were informed about this specific procedure, just before the ham and cheese sandwich auction started.

After getting fully familiarized with the auction mechanism and procedures, subjects were shown a ham and cheese sandwich packed in a brandless package. Although this product was familiar to all participants, they were asked to pass it around and inspect it closely prior to the auction as if it were a product they 
would know less about (Alfnes, 2007). Since it is possible that exposure to food during the experiment can increase hunger, all subjects were exposed to the products in the same amount of time. Participants in the "present" treatment were told that a sandwich would be delivered to each of the highest bidders right after the auction while participants in the "future" treatments were informed that a sandwich would be delivered to each of the highest bidders in 1 week. The monitor made clear to subjects in the "future" treatments that the highest bidders of the auction each would be getting a fresh sandwich 1 week later. Depending on the treatment selected, subjects in the "future" treatments were also informed that they would be required to pay for their sandwiches immediately after the auction or at pick-up 1 week later. The participants then bid in five real auction rounds for a sandwich. After all rounds were finished, a binding round was then randomly chosen to determine the final highest bidders of the auction. Although no feedback was provided between rounds, Corrigan et al. (2012) found that even without price feedback, repeated rounds improve auction performance. Our data show that even without feedback only 36 out of 252 subjects (roughly $14.2 \%$ ) bid exactly the same in all five rounds but that the vast majority $(85.8 \%)$ does not.

The participants were also asked to fill out a questionnaire that included sociodemographic- and health-related questions as well as a question about the time since their last meal. Questions about subjects' preferences for ham and cheese sandwiches, as well as their frequency of consumption of this type of sandwich, were also included.

\section{Results and discussion}

Figure 2 displays the mean and median bids across rounds. Subjects in the sessions before lunch $(1 \mathrm{pm})$ were willing to pay a higher price than subjects in the after lunch treatments $(3 \mathrm{pm})$. In addition, subjects bidding to buy the sandwich immediately after the session (Present Treatment) bid higher than those bidding to buy the sandwich 1 week later (Future Treatment).

Mean and median bids for those who participated in the future treatments, broken down by when the payment for the sandwich was required and time of the session in the day, are shown in Fig. 3. Subjects who had to pay in the future show no difference in mean or median bids when comparing the before-lunch and the after-lunch sessions. This is an indication that when no economic sacrifice was imposed on bidding behavior, hunger status does not significantly affect bids. On the other hand, when subjects had to pay immediately after the session (pay now) for the sandwich that was going to be delivered 1 week later, they bid much lower when in the after-lunch session (when they are likely to be satiated) than when in the before-lunch session (when they are likely to be hungry).

Evidence of projection bias is depicted in Figs. 4 and 5 where the kernel density estimates of bidding behavior in the present and future treatments, respectively, are shown. In addition, Figs. 6 and 7 show the kernel density estimates of bids in the before and after lunch treatments, respectively. The effect of hunger on bids in the present treatments (i.e., sandwich is delivered right after the auction) are depicted in Fig. 4. As shown, the distribution of bids in the before-lunch treatment is shifted more to the right with respect to the after-lunch treatment. This implies that when subjects are (likely) hungry, they bid more for the sandwich. A Kolmogorov-Smirnov test rejects 


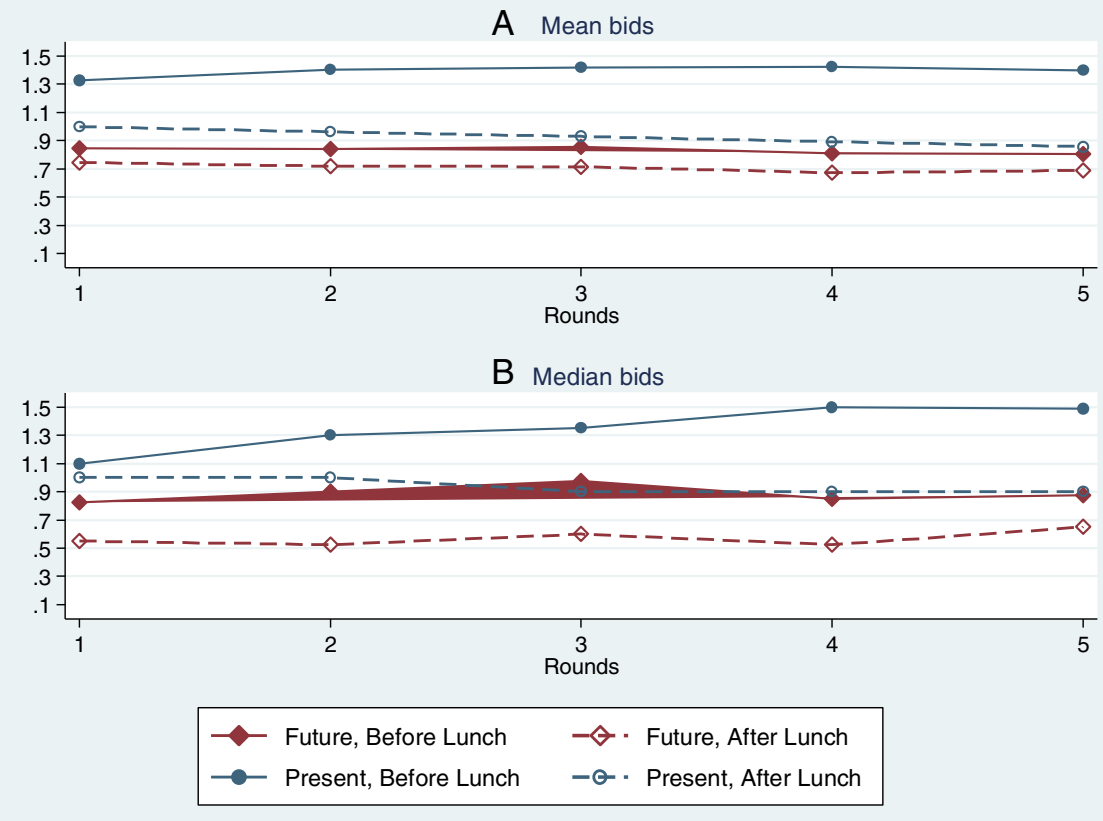

Fig. 2 Mean and median bids across rounds

equality of the two distributions $(p$-value $<0.001)$ in favor of the hypothesis that the distribution of bids at the before-lunch treatment contains larger values. The largest difference between the distribution functions in this direction is 0.38 . The left part of Fig. 5 shows the effect of hunger in the future treatments (i.e., sandwich is delivered with a time delay of 1 week) when payment was required in

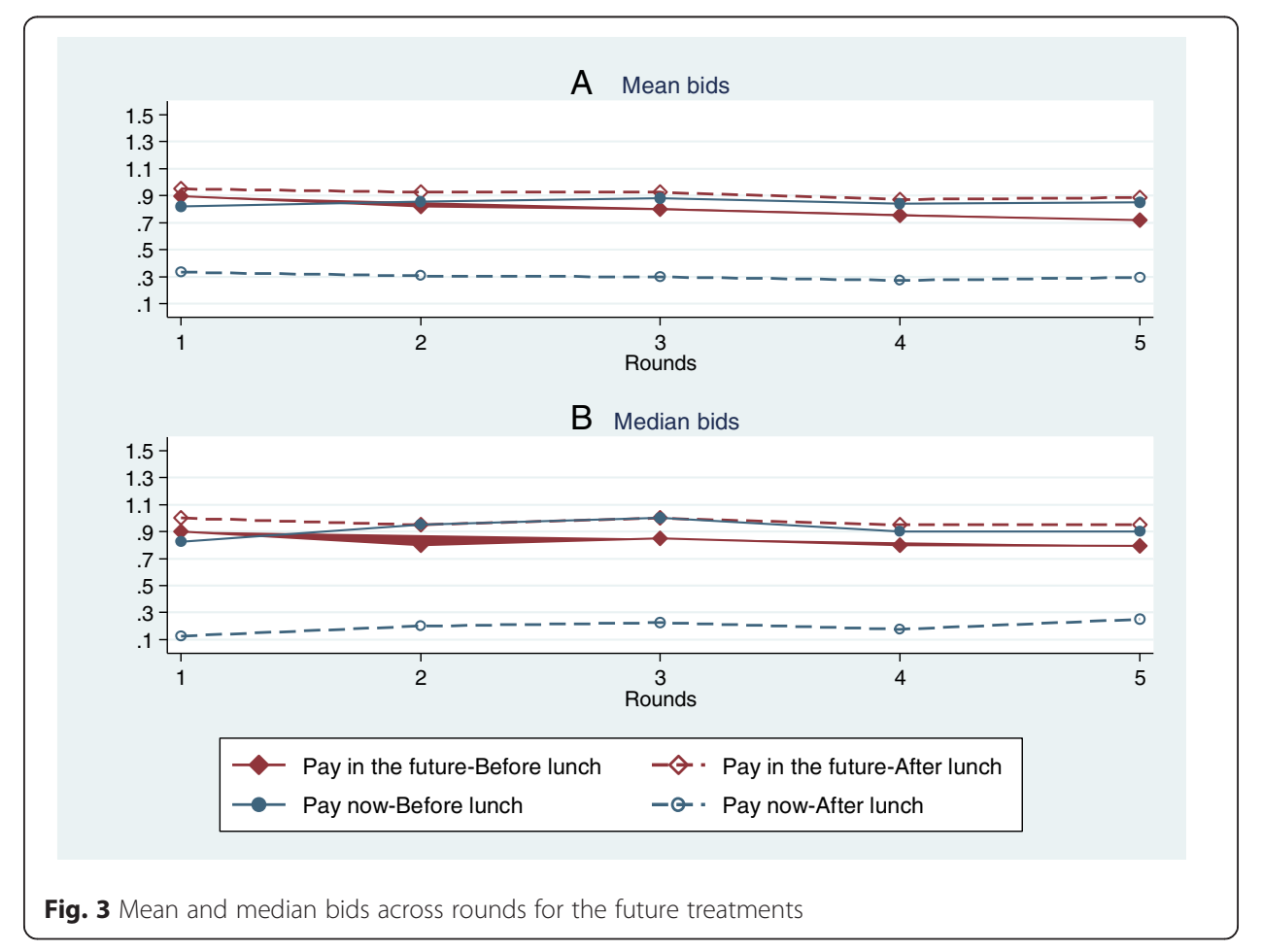




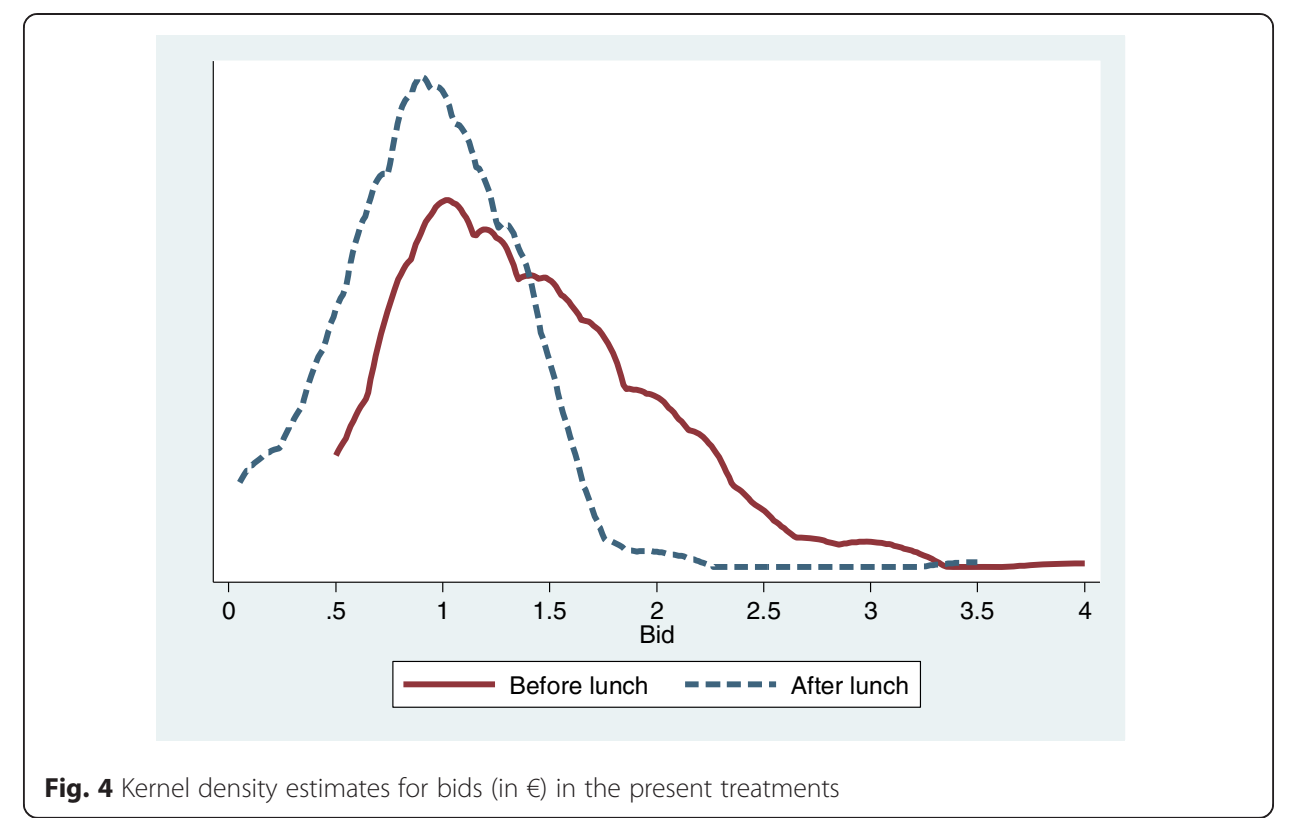

advance (i.e., right after the auction). Given that the distribution of the beforelunch bids is shifted to the right, this figure also implies the effect of hunger. However, given that the distribution is shifted more to the right as compared with Fig. 4, it shows that subjects over-predict their future hunger status. This is supported by a Kolmogorov-Smirnov test which rejects equality of the two distributions ( $p$-value $<0.001)$ in favor of the hypothesis that the distribution of bids at the before-lunch treatment contains larger values. The largest difference between the distribution functions in this direction is 0.71 which is almost double the difference

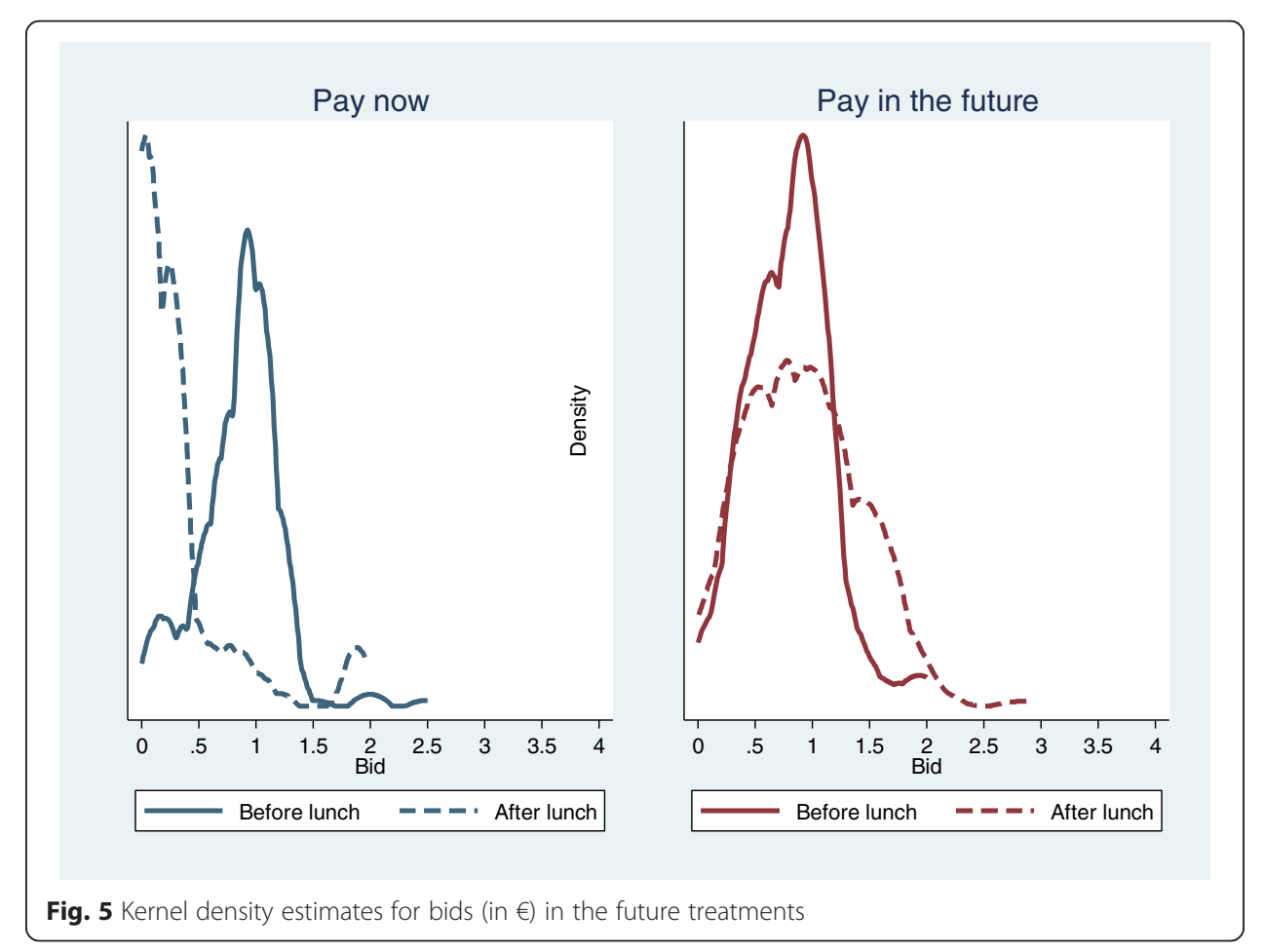




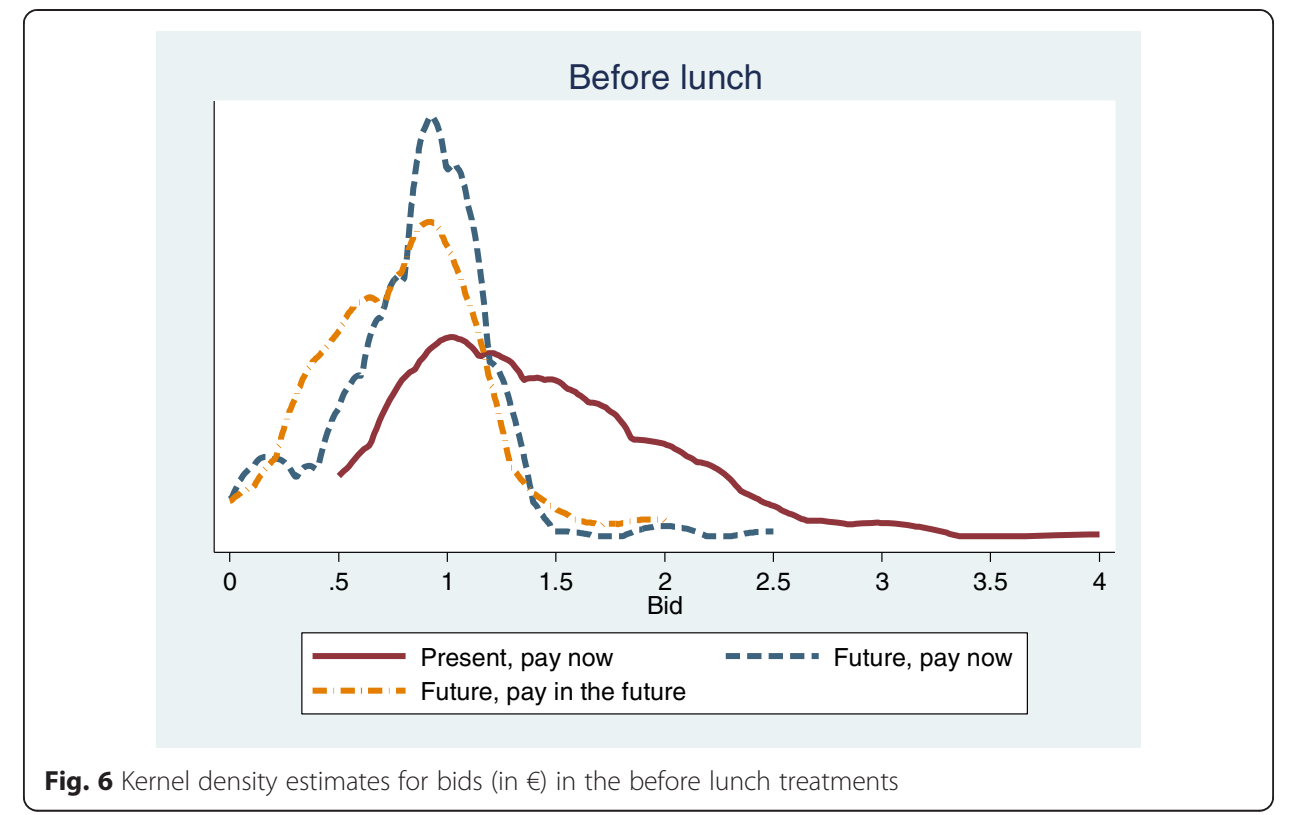

shown in Fig. 4. Similarly, it seems that subjects under-predict their level of satiation in the future, since the distribution of bids in the after-lunch treatment is shifted much more to the left as compared with Fig. 4. The difference in the gaps of the two distributions (before- and after-lunch) in the present and future treatments is evidence of projection bias. Trivially, the right panel of Fig. 5 shows that without economic costs imposed in the auction, hunger status does not affect bids. Distributions of bids in the before- and after-lunch treatments are considerably overlapping. While a Kolmogorov-Smirnov test rejects equality of the two distributions $(p$-value $=0.005)$ in favor of the hypothesis that the distribution of bids at the before-lunch treatment contains smaller values. The largest difference between the

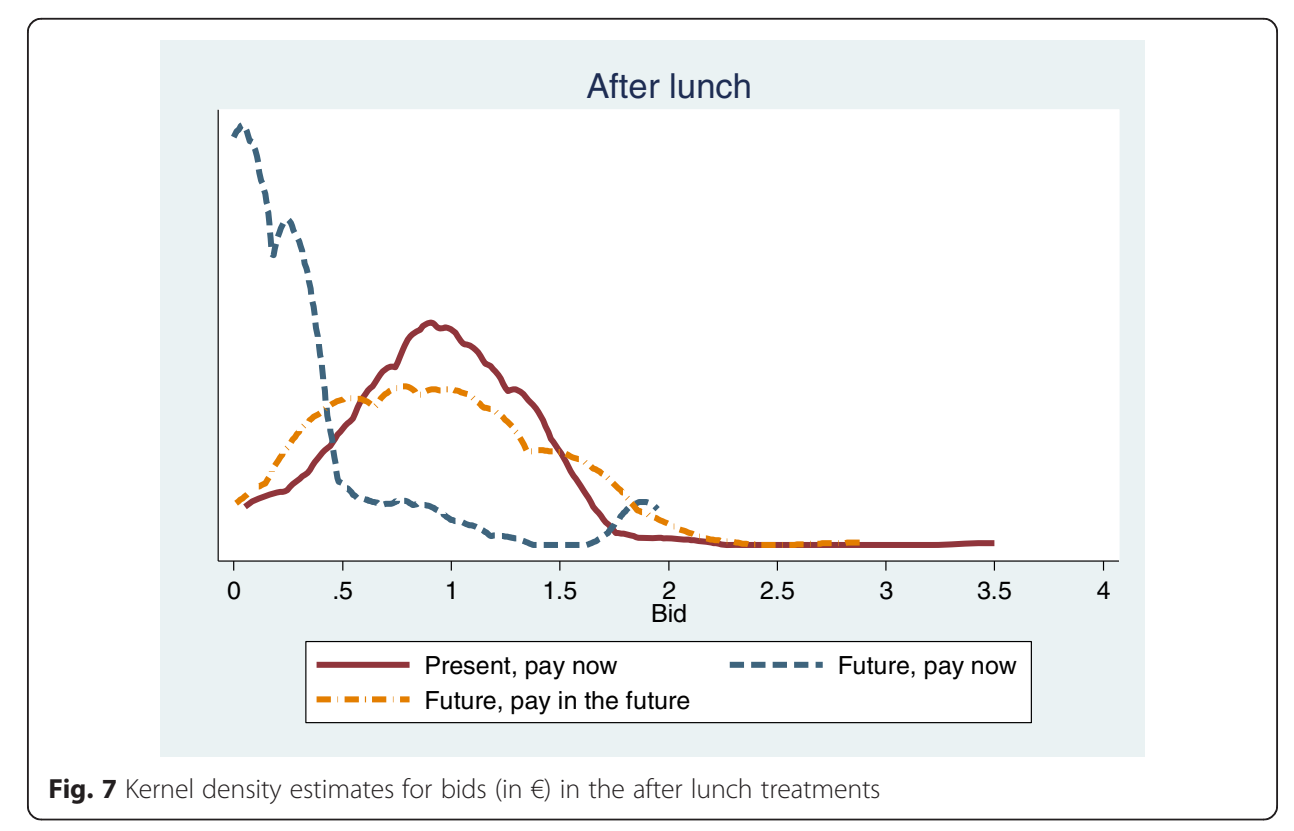


distribution functions is 0.19 , which is considerably smaller than the differences in Fig. 4 and the left panel of Fig. 5.

To quantify the effect of projection bias and also explore whether the differences discussed so far hold under the scrutiny of conditional analysis, we estimated a random effects regression model, where the regression function is specified as:

$$
\text { Bid }_{i t}=\left(\begin{array}{c}
b_{0}+b_{1} \text { Future }_{i}+b_{2} \text { AfterLunch }_{i}+\text { f }_{3} \text { FuturePay }_{i}+\text { b }_{4} \text { LastMeal }_{i} \\
+b_{5} \text { Futur }_{i} \times \text { AfterLunch }_{i}+b_{6} \text { FuturePay }_{i} \times \text { AfterLunch }_{i} \\
+b_{7} \text { FuturePay }_{i} \times \text { LastMeal }_{i}+b_{8} \text { Future }_{i} \times \text { LastMeal }_{i} \\
+b_{9} \text { Round }_{2 i}+b_{10} \text { Round }_{3 i}+b_{11} \text { Round }_{4 i}+b_{12} \text { Round }_{5 i}
\end{array}\right)+e_{i t}+u_{i}
$$

where $i$ is a subscript for the individuals and $t$ is a subscript indicating the time dimension of the data (i.e., rounds). ${ }^{3}$ The random error term $u_{i}$ is heterogeneity-specific to the individual and is constant over all time periods. The random error term $e_{i t}$ is specific to a particular observation and incorporates the time dimension into the model. With respect to the variables, Future is a dummy indicating whether subjects were bidding to get the sandwich 1 week later, AfterLunch is a dummy for treatments that were conducted at $3 \mathrm{pm}$, FuturePay is a dummy indicating whether in the Future treatments subjects had to pay 1 week later or right after the auction, LastMeal is time since last meal (in hours) and Round are round dummies. We estimate this specification with and without demographics/attitudinal variables, as shown in Table 2, and find that results are fairly robust. The demographics/attitudinal variables included in one of the specifications include variables consistent with the variable name: dummy for males, age, dummy for students, income dummies, self-reported body mass index (BMI), dummy for whether the respondent likes cheese and ham sandwiches (LikeHam) and dummies for how frequently subjects eat ham and cheese sandwiches. ${ }^{4}$

Equation (1) includes several interaction terms to help capture the differential effects evident in Figs. 2, 3, 4 and 5. To test whether the model with the interaction terms fits the data significantly better, we fitted the random effects model with maximum likelihood (ML) and performed a Likelihood Ratio (LR) test. ${ }^{5}$ The model with the interaction terms fits the data significantly better $(\mathrm{LR}=35.96, p$-value $=0.00$ and $\mathrm{LR}=34.63$, $p$-value $=0.00$ for models (1) and (2) of Table 2, respectively).

Coefficient estimates from equation (1) are shown in Table 2. However, interpretation of the interacted variables is not straightforward. Marginal effects for each of the interacted variables needs to take into account the other interacted variables as well (Drichoutis and Nayga, 2011). For the Future variable this would be:

$$
\frac{\partial \text { Bid }}{\partial \text { Future }}=b_{1}+b_{5} \text { AfterLunch }+b_{8} \text { LastMeal } \text {. }
$$

which can then be evaluated for AfterLunch $=1$ or 0 and the median value of LastMeal. Similar derivations are in place for the AfterLunch, FuturePay and LastMeal variables. Marginal effects for the interacted variables appear in Table 3. Standard errors for the expressions have been calculated using the delta method. These results largely confirm what is seen by observation of Figs. 2, 3, 4 and 5. For example, subjects who bid to buy the sandwich for future consumption (1 week later) bid less than subjects who bid to buy the sandwich right after the auction. ${ }^{6}$ Subjects who bid to get the sandwich in the 
Table 2 Coefficient estimates from Random Effects Regression

\begin{tabular}{|c|c|c|c|c|}
\hline & \multicolumn{2}{|l|}{ (1) } & \multicolumn{2}{|l|}{ (2) } \\
\hline & Coef. & Std. Error & Coef. & Std. Error \\
\hline Constant & 0.046 & -0.305 & $1.216^{\mathrm{a}}$ & -0.089 \\
\hline Future & $-0.239^{\mathrm{a}}$ & -0.096 & $-0.225^{\mathrm{a}}$ & -0.103 \\
\hline AfterLunch & $-0.341^{\mathrm{a}}$ & -0.077 & $-0.356^{\mathrm{a}}$ & -0.083 \\
\hline Future $\times$ AfterLunch & $-0.268^{\mathrm{a}}$ & -0.136 & $-0.291^{\mathrm{a}}$ & -0.137 \\
\hline FuturePay & -0.118 & -0.11 & -0.118 & -0.102 \\
\hline FuturePay $\times$ AfterLunch & $0.702^{\mathrm{a}}$ & -0.15 & $0.727^{\mathrm{a}}$ & -0.149 \\
\hline LastMeal & $0.054^{a}$ & -0.017 & $0.056^{\mathrm{a}}$ & -0.018 \\
\hline Future $\times$ LastMeal & $-0.085^{\mathrm{a}}$ & -0.019 & $-0.087^{\mathrm{a}}$ & -0.019 \\
\hline FuturePay $\times$ LastMeal & 0.005 & -0.025 & 0.011 & -0.02 \\
\hline Round $_{2}$ & -0.002 & -0.023 & 0.003 & -0.023 \\
\hline Round $_{3}$ & -0.004 & -0.026 & 0.001 & -0.026 \\
\hline Round $_{4}$ & -0.035 & -0.029 & -0.03 & -0.029 \\
\hline Round $_{5}$ & -0.047 & -0.03 & -0.042 & -0.03 \\
\hline Males & -0.077 & -0.066 & - & - \\
\hline Age & $0.026^{a}$ & -0.006 & - & - \\
\hline Student & $0.129^{b}$ & -0.076 & - & - \\
\hline $\ln C_{2}$ & -0.028 & -0.089 & - & - \\
\hline $\ln c_{3}$ & 0.115 & -0.093 & - & - \\
\hline $\ln C_{4}$ & -0.044 & -0.101 & - & - \\
\hline BMI & 0.015 & -0.011 & - & - \\
\hline LikeHam & 0.119 & -0.129 & - & - \\
\hline FreqHam $_{2}$ & 0.067 & -0.076 & - & - \\
\hline $\mathrm{FreqHam}_{3}$ & 0.06 & -0.076 & - & - \\
\hline $\mathrm{FreqHam}_{4}$ & -0.015 & -0.081 & - & - \\
\hline N & 1245 & & 1255 & \\
\hline
\end{tabular}

Future before lunch bid $0.39 €(0.38 €$ based on model (2)) lower than subjects who bid to get the sandwich immediately after the auction before lunch. This effect is roughly equivalent to $40 \%$ of the average predicted WTP value for the sandwich which is estimated at $0.97 €$. Similarly, subjects who bid to get the sandwich in the Future after lunch bid $0.66 €$ lower than subjects who bid to get the sandwich immediately after the auction after lunch (roughly $68 \%$ of the average predicted WTP). Thus, the (negative) effect of getting the sandwich 1 week later is even larger when subjects are satiated at the time of the auction $(-0.66 €$ vs. $-0.39 €)$.

One potential explanation for why subjects bid less when the sandwich is going to be delivered 1 week later is time discounting. Subjects are discounting the value of the sandwich 1 week later in present value. Another explanation that we cannot rule out (even though we took every precaution to reassure subjects this will not be the case) is uncertainty about delivery of the sandwich. ${ }^{7}$ If some subjects were uncertain about whether the experimenter would actually deliver the sandwich 1 week later as promised, then these subjects would be motivated to shade their bids to account for the risk of not actually getting the sandwich. If we couple these two explanations with satiation at the time of the auction (after lunch sessions) which makes a sandwich look less 
Table 3 Marginal effects for interacted variables

\begin{tabular}{|c|c|c|c|c|c|}
\hline & & \multicolumn{2}{|l|}{ (1) } & \multicolumn{2}{|l|}{ (2) } \\
\hline & & Marginal effect & Std. error & Marginal effect & Std. error \\
\hline \multirow[t]{2}{*}{ Future } & Afterlunch = 1 & $-0.655^{\mathrm{a}}$ & 0.105 & $-0.667^{\mathrm{a}}$ & 0.108 \\
\hline & Afterlunch $=0$ & $-0.387^{\mathrm{a}}$ & 0.079 & $-0.377^{a}$ & 0.086 \\
\hline \multirow[t]{3}{*}{ AfterLunch } & Future $=1$, FuturePay $=1$ & 0.093 & 0.102 & 0.081 & 0.101 \\
\hline & Future $=1$, FuturePay $=0$ & $-0.609^{\mathrm{a}}$ & 0.109 & $-0.646^{\mathrm{a}}$ & 0.110 \\
\hline & Future $=0$, FuturePay $=0$ & $-0.341^{\mathrm{a}}$ & 0.077 & $-0.356^{\mathrm{a}}$ & 0.083 \\
\hline \multirow[t]{2}{*}{ FuturePay } & Afterlunch $=1$ & $0.592^{a}$ & 0.120 & $0.628^{a}$ & 0.122 \\
\hline & Afterlunch $=0$ & -0.110 & 0.090 & -0.099 & 0.087 \\
\hline \multirow[t]{3}{*}{ LastMeal } & Future $=1$, FuturePay $=1$ & -0.026 & 0.023 & -0.02 & 0.018 \\
\hline & Future $=1$, FuturePay $=0$ & $-0.031^{\mathrm{a}}$ & 0.009 & $-0.031^{\mathrm{a}}$ & 0.007 \\
\hline & Future $=0$, FuturePay $=0$ & $0.054^{\mathrm{a}}$ & 0.017 & $0.056^{\mathrm{a}}$ & 0.018 \\
\hline N & & 1245 & & 1255 & \\
\hline
\end{tabular}

Standard errors are robust standard errors to arbitrary heteroskedasticity

${ }^{a}=$ Significance at 5 and $10 \%$ level. This table presents several conditional marginal effects. For example, "Future, AfterLunch $=1$ " refers to the effect of Future conditional on AfterLunch taking the value of one. Likewise, "AfterLunch, Future $=1$, FuturePay $=0^{\prime \prime}$ captures the effect of timing of the session in the treatments that promised delivery of the good in the future and subjects had to pay in advance

appealing, shading a bid by (on average) as much as 66 cents sounds sensible. In all, the first two rows of Table 3 show that subjects value the sandwich more when it is offered for immediate consumption and value it even more if this occurs before lunch, even when controlling for time since their last meal.

The next three rows of Table 3 evaluate the effect of hunger (before- vs. after-lunch sessions) for the different treatments. Some studies suggest that people have strong preferences about the time of the day when they consume particular foods (Gilbert and Wilson, 2007; Kramer, Rock, and Engell, 1992; Birch, Billman, and Richards, 1984). When in a satiated state, people consider the prospect of a meal not very appetizing if they have just finished eating (Gilbert, 2006) or are less likely to purchase food than those who have yet to eat (Hoffman et al., 1993). Although previous studies focus specifically on the "time of the day" effect on bidding behavior by conducting auctions throughout the day (Demont et al., 2012, 2013a, 2013b; Morawetz, De Groote, and Chege, 2011; Hoffman et al., 1993; Menkhaus et al., 1992), we use the 2-hour difference between auctions to allow for variation in hunger, not to measure "time of day" impact.

The effect of the before-and after-lunch treatments for those participants who bid to receive the sandwich in 1 week's time is a key effect because it allows us to quantify the effect of projection bias. The estimate of $-0.34 €(-0.36 €$ for model $(2))$ is the quantified effect of hunger in the present treatments and roughly corresponds to the difference of distributions in Fig. 4. This implies that satiated subjects are, on average, willing to pay $0.34 €$ less than hungry subjects for the sandwich. When subjects have to predict their future WTP based on their current tastes (current level of hunger), the effect of hunger almost doubles to $0.61 €(0.65 €$ based on model (2)) which is equivalent to $63 \%(67 \%)$ of the average predicted WTP. This corresponds to the left part of Fig. 5 and is the result of over-predicting hunger and under-predicting satiation. Thus, the difference between these two effects $(0.61 €$ vs. $0.34 €)$ can be attributed to projection bias. Finally, hunger levels do not significantly affect bids when subjects are bidding in the future 
delivery treatments and do not have to feel the costs of their decision right away (i.e., future payment treatment). This last result corresponds to the right part of Fig. 5 .

The effect of paying in the future for the sandwich that was going to be delivered 1 week later versus paying in advance is only significant in the after lunch sessions. Subjects increase their bids by almost 60 cents (63 cents for model(2)) when they have to pay upon delivery of the sandwich (and not right after the end of the auction) and when they are satiated (these are equivalent to 62 and $65 \%$ respectively of the average predicted WTP). The difference for hungry participants is neither economically nor statistically significant.

The last three rows of Table 3 show the effect of time since last meal on bids conditional on the treatment variables. The largest effect is observed for the present treatments; for every hour since their last meal, subjects increase their bids by 0.05 cents. Interestingly, time since last meal negatively affects bids in the treatments that promised delivery of the sandwich 1 week later, although the effects are much smaller. Perhaps there is a mechanism in place that acts proactively for those with low hunger levels (bid more to get the sandwich in the future in case I get hungry) and protectively for those with high hunger levels (bid more to get the sandwich now to satiate my appetite). ${ }^{8}$

Regarding the remaining variables, the round dummy variables are neither economically nor statistically significant. This is also evident in Figs. 2 and 3, where lines are quite stable over rounds. There is a slight decrease of bids in round five which could be attributed to end game effects. Some demographic effects are also evident in Table 2. For example, age has a positive statistically significant effect on bidding, and students (Student) bid more than non-students by $€ 0.13$ (equivalent to $13 \%$ of average predicted WTP). Other variables like income, Body Mass Index (BMI), liking ham sandwiches and eating ham sandwiches regularly are not significant.

\section{Conclusion}

Over the past few years, there has been a growing trend towards integrating behavioral evidence from psychology to the usual lines of economic research. Much has been accomplished on this front since Rabin (1998) where he discussed the importance of linking Psychology and Economics. DellaVigna (2009) then added that "hopefully, 10 years from now, we will be able to assess quantitatively which psychological factors matter in which decisions". In this study, we tried to explore how (projection) biases that are not predicted by classical microeconomic theory affect subjects' valuation within the context of experimental economic auctions and how this effect is mediated by hunger and preference for immediate gratification. Loewenstein (1996) states that when people are in what is called a "hot" state (e.g., angry, hungry, or in pain), it is difficult to imagine how they would feel or what they might do if they were in a "cold" state. These gaps lead to errors in predicting behavior. One implication of this projection bias is that people behave differently when in hunger or satiation. In fact, there is considerable research demonstrating that hunger not only influences taste evaluations (e.g., Scott, 1990; Fantino, 1984), but also influences attitudes towards food (Lozano et al. 1999) and attitudes towards shopping (Nisbett and Kanouse, 1968; Mela et al., 1997; Gilbert et al., 2002). For example, people may change their behavioral intentions towards the purchase and consumption of food when they are hungry. Hunger has 
also been shown to affect risk aversion (Symmonds et al., 2010), which may subsequently affect subjects' valuation for a product.

In this study, we examined the role of projection bias in experimental auctions by assessing the bidding behavior of hungry and non-hungry subjects on a perishable food product that was going to be given either right after the auction or in 1 week's time. Hence, we investigated not only the role of hunger but also the role of immediate gratification on subjects' valuations. Our results generally suggest that subjects who are offered the sandwich right after the auction are willing to pay more than those who had to wait 1 week to get their product. Time discounting and perhaps some uncertainty on whether the sandwich was actually going to be delivered could rationalize this result. Preferences tend to be clearly present-biased due to a need for immediate gratification and doubts about future necessities.

On the projection bias issue, we found that when subjects have to predict their future WTP from their current tastes, they tend to over-predict their hunger and underpredict satiation. Thus, the effect of hunger on bids almost doubles due to projection bias. Subjects are willing to pay 34 cents more when they are hungry as compared to when they are satiated but this effect almost doubles to 61 cents when subjects have to predict their future tastes.

Our findings suggest the important roles of hunger in examination of projection bias in experimental auctions. Our results have significant implications for future experimental auction designs. Experimental auctions are becoming a very popular tool used by economists to elicit consumers' WTP for food products. For perishable food products that are intended for immediate consumption, projection bias is less likely to be an issue although hunger would still play a significant role in shaping bidding behavior. However, for food products that can be stored for longer time and therefore intended for future consumption, projection bias can be an issue. As we show, current tastes significantly affects bidding behavior of a planned future consumption. If not taken into account, part of bids will include biased estimates of consumer preferences. Our results show that projection bias is significant even for 1 week's time. Our findings imply that both hunger levels and desire for immediate consumption (or conversely for delayed consumption) should be measured so that researchers using experimental auctions to examine food products can control for these factors in the WTP models.

Our results also have practical and important implications for marketing products. For example, results in this paper suggest that food delivery businesses (i.e., those that deliver food products from stores to specific locations such as homes) should strive to significantly reduce delivery times and not ask customers to pay well in advance of delivery. It might also be better to advertise or promote products before meals than right after meals. Results might also have implications on whether stores should allow taste tests in the store or not, since this could affect the level of hunger and quest for immediate gratification among shoppers. These results correspond to findings by Gilbert et al. (2002), which showed that shoppers who were given a muffin to eat before entering a supermarket were more likely to restrict their purchases in their shopping list.

While our findings are interesting and useful for designing future experimental auction studies involving food, we have to recognize that they are still based on specific contexts as in any experimental economics study. Specifically, our results are based on valuations for a familiar product. Future research should test the robustness of our 
findings with unfamiliar products. It is possible that the roles of hunger and immediate gratification could be less important when valuing products that are less familiar to subjects. For less familiar products, one could also test how experienced reward processes interact with hunger and immediate gratification by letting subjects taste a small sample of the food while deciding how much to bid, similar to one of the experiments conducted in Bushong et al. (2010).

\section{Endnotes}

${ }^{1}$ We base our interpretation of the impact of hunger on the "After Lunch" variable and not on time since "Last Meal". Time since last meal only measures the last time a subject ate anything. This could be a full meal or a small snack. For example, several people in the before and the after lunch sessions reported having eaten something half an hour before the session. We expect that for people in the before lunch session this would have been a snack while for people in the after lunch sessions this might have been a full meal. If we would have used solely the "Last Meal" variable to measure the impact of hunger, we would have implicitly treated subjects in the before and after lunch sessions equivalently regardless of the type of food they consumed. We use both time since "Last Meal" and the "After Lunch" measures in our econometric models, therefore the effect of the "After Lunch" dummy is conditional on time since "Last Meal". The "After Lunch" variable allows us to group together subjects that we would a priori expect to be more or less hungry. The "Last Meal" variable controls for within group variation in hunger levels. Both measures are significantly correlated $(\rho=-0.40, p$-value $<0.001)$ as well. To illustrate how time since last meal differs by time of the day sessions, Fig. 1 depicts histograms of time since last meal for the before and after lunch sessions. As evident, in the after lunch session, time since last meal was significantly shorter than in the before lunch session.

${ }^{2}$ Our experimental design focuses on testing for just one form of projection bias since our subjects have to project their current tastes in a future time where similar circumstances to the present time might apply (e.g., bid before lunch when hungry to get the sandwich in one week before lunch when subject expects to be hungry again). A more complex form of projection bias would entail having subjects projecting their current tastes in a future time where circumstances might be expected to differ to the present (e.g., bid before lunch when hungry to get the sandwich in one week after lunch when subject expects not to be hungry). Although this is also a form of projection bias, we focus only on the simpler definition as in the second case, consumers projections are confounded both by the time delay and by uncertainty about the circumstances that would prevail in a time not similar to the present.

${ }^{3}$ Zero bids represent only $3.5 \%$ of total bids (44 observations out of 1,260). Given the small amount of zero bidding behavior, we did not pursue a Tobit or a double hurdle model. Our analysis was performed in Stata ver. 11.

${ }^{4}$ Dummies for the frequency of consumption of ham and cheese sandwiches indicate consumption "once a month" (FreqHam $)_{2}$, "once per week" (FreqHam 3 ) and "three times per week or more often" (FreqHam 4 ). The excluded category is "never".

${ }^{5}$ The ML estimator has the same properties as the Feasible Generalized Least Squares (FGLS) and results using the ML estimator versus the FGLS are practically identical. 
${ }^{6}$ Note that the effect is evaluated at the median of the LastMeal variable (which captures how hungry someone is at the time of the auction).

${ }^{7}$ An additional concern is that the future delivery of the sandwich included the additional cost of coming back to pick up the sandwich. We believe that this would be less of a concern given that our auctions took place at the main University building, less than $50 \mathrm{~m}$ away from the classroom building and the main library. Since the experiments were carried out during the regular semester, students were supposed to follow the same class schedule every week. That is, if they were free on a Tuesday at $3 \mathrm{pm}$ to take part in the experiment, they would likely be free the following Tuesday at $3 \mathrm{pm}$ to pick up the sandwich. In addition, there was certain flexibility and students could come either a little earlier or later than their expected pick up time.

${ }^{8}$ An additional reason why subjects with higher hunger levels bid less to get the sandwich in the future is the concept of an outside option. Subjects with higher hunger levels may prefer to spend their money on food once the auction is finished instead of paying for a sandwich they will only get a week later. Although the outside option has not been studied in the context of fourth price auctions, Kirchkamp et al. (2009) found that in second price auctions the introduction of outside options has only small effects as compared to a first price auction. In addition, availability of outside options might be tempting as an explanation of the effect of paying in the future on bidding behavior. For example, if the highest bidder of the auction does not have to pay now, s/he is essentially getting an option of changing his/her mind in one week and not committing to his/her current decision. However, this does not explain why the option mechanism fails to manifest in the before lunch treatments. Subjects in the before lunch treatments did not bid differently when they had to pay right after the auction or in one week's time. Hence, it would be hard to argue that the option or commitment explanation only applies in the after lunch sessions.

Competing interests

The authors declare that they have no competing interests.

Authors' contributions

TB, ACD, LH designed the experiments, TB conducted the experiments, ACD analyzed the data, TB, ACD, LH wrote the paper. All authors read and approved the final manuscript.

\section{Author details}

${ }^{1}$ Department of Agricultural Economics, E.T.S. Ingenieros Agrónomos Universidad Politécnica de Madrid, 28040 Madrid, Spain. ${ }^{2}$ Department of Agricultural Economics \& Rural Development Agricultural, University of Athens, lera Odos 75,

11855 Athens, Greece. ${ }^{3}$ Food and Resource Economics Department, University of Florida Gainesville, Florida, USA.

Received: 22 December 2014 Accepted: 7 August 2015

Published online: 02 September 2015

References

Alfnes F (2007) Willingness to Pay Versus Expected Consumption Value in Vickrey Auctions for New Experience Goods. Am J Agric Econ 89(4):921-931

Birch LL, Billman J, Richards SS (1984) Time of Day Influences Food Acceptability. Appetite 5(2):109-116

Bushong B, King LM, Camerer CF, Rangel A (2010) Pavlovian Processes in Consumer Choice: The Physical Presence of a Good Increases Willingness to Pay. Am Econ Rev 100(4):1556-1571

Busse MR, Pope DG, Pope JC, Silva-Risso J (2012) Projection Bias in the Car and Housing Markets. Working Paper 18212. National Bureau of Economic Research, Cambridge, MA, http://www.nber.org/papers/w18212

Conlin M, O'Donoghue T, Vogelsang TJ (2007) Projection Bias in Catolog Orders. Am Econ Rev 97(4):1217-1249

Corrigan J, Drichoutis A, Lusk J, Nayga RM Jr, Rousu M (2012) Repeated Rounds with Price Feedback in Experimental Auction Valuation: An Adversarial Collaboration. Am J Agric Econ 94(1):97-115

Corrigan JR, Rousu MC (2006a) The Effect of Initial Endowments in Experimental Auctions American Journal of Agricultural Economics 88 (2):448-457

Corrigan JR, Rousu MC (2006b) Posted Prices and Bid Affiliation: Evidence from Experimental Auctions. American Journal of Agricultural Economics. 88(4)1078-1090

DellaVigna S (2009) Psychology and Economics: Evidence from the Field. J Econ Lit 47(2):315-372 
Demont M, Rutsaert P, Ndour M, Verbeke W (2013a) Reversing Urban Bias in African Rice markets: Evidence from Senegal. World Development 45:63-74

Demont M, Rutsaert P, Ndour M, Verbeke W, Seck PA, Tollens E (2013b) Experimental Auctions, Collective Induction and Choice Shift: Willingness-to-pay for Rice Quality in Senegal. European Review of Agricultural Economics 40(2):261-286

Demont M, Zossou E, Rutsaert P, Ndour M, Van Mele P, Verbeke W (2012) Consumer valuation of improved rice parboiling technologies in Benin. Food Qual Prefer 23:63-70

Depositario DT, Nayga RM Jr, Wu X, Laude TP (2009) Should students be used as subjects in experimental auctions? Econ Lett 102(2):122-124

Drichoutis AC, Nayga RM Jr (2011) Marginal Changes in Random Parameters Ordered Response Models with Interaction Terms. Econ Rev 30(5):565-576

Fantino M (1984) Role of Sensory Input in the Control of Food Intake. J Auton Nerv Syst 10(3/4):347-358

Fox JA (1995) Determinants of Consumer Acceptability of Bovine Somatotropine. Rev Agric Econ 17:51-62

Gilbert D (2006) Stumbling on Happiness. Knopf, New York

Gilbert D, Wilson TD (2007) Prospection: Experiencing the Future. Science 317(5843):1351-1354

Gilbert D, Gill MJ, Wilson TD (2002) The Future Is Now: Temporal Correction in Affective Forecasting. Organ Behav Hum Decis Process 88(1):430-444

Hoffman E, Menkhaus DJ, Chakravarti D, Field RA, Whipple GD (1993) Using Laboratory Experimental Auctions in Marketing Research: A Case Study of New Packaging for Fresh Beef. Mark Sci 12(3):318-338

Jack FR, Piacentini MG, Schröder JA (1997) Perception of Fruit as a Snack: A Comparison with Manufactured Snack Foods. Food Qual Prefer 8(3):175-182

Kirchkamp O, Poen E, Reiß JP (2009) Outside options: Another reason to choose the first-price auction. Eur Econ Rev 53(2):153-169

Kramer FM, Rock K, Engell D (1992) Effects of Time of Day and Appropriateness on Food Intake and Hedonic Ratings at Morning and Midday. Appetite 18(1):1-13

Loewenstein G (1996) Out of Control: Visceral Influences on Behavior. Organ Behav Hum Decis Process 65(3):272-292 Loewenstein G (2005) Projection Bias in Medical Decision Making. Med Decis Making 25(1):96-104

Loewenstein G, O'Donoghue R, Rabin M (2003) Projection Bias in Predicting Future Utility. Q J Econ 118(4):1209-1248

Lozano DI, Crites SL, Aikman SN (1999) Changes in Food Attitudes as a Function of Hunger. Appetite 32(2):207-218

Lusk J, Feldkamp T, Schroeder T (2004a) Experimental Auction Procedure: Impact on Valuation of Quality Differentiated Goods. American Journal of Agricultural Economics 86:389-405

Lusk JL, House LO, Valli C, Jaeger SR, Moore M, Morrow JL, Traill WB (2004b) Effect on information about benefits of biotechnology on consumer acceptance of genetically modified food: evidence from experimental auctions in the United States, England and France. European Review of Agricultural Economics 31(2):180-204

Mela DJ, Aaron JL, Gatenby SJ (1997) Relationships of Consumer Characteristics and Food Deprivation to Food Purchasing Behavior. Physiol Behav 60(5):1331-1335

Menkhaus DJ, Borden GW, Whipple GD, Hoffman E, Field RA (1992) An Empirical Application of Laboratory Experimental Auctions in Marketing Research. J Agric Resour Econ 17(1):44-55

Morawetz UB, De Groote H, Chege SK (2011) Improving the Use of Experimental Auctions in Africa: Theory and Evidence. J Agric Resour Econ 36(2):263-279

Nisbett RE, Kanouse DE (1968) Obesity, Hunger, and Supermarket Shopping Behavior. Proc Annu Convention Am Psycology Assoc 3:683-684

Rabin M (1998) Psychology and Economics. J Econ Lit 36(1):11-46

Read D, Van Leeuwen B (1998) Predicting Hunger: The Effects of Appetite and Delay on Choice. Organ Behav Hum Decis Process 76(2):189-205

Scott TR (1990) Gustatory Control of Food Selection. In: Stricker EM (ed) Handbook of Behavioral Neurobiology, vol 10. Plenum Press, New York, pp 243-263

Shogren JF, Margolis M, Koo C, List JA (2001) A Random Nth-Price Auction. J Econ Behav Organ 46(4):409-421

Soler F, Gil JM, Sánchez M (2002) Consumers' acceptability of organic food in Spain. Results from an experimental auction market. Br Food J 104(8):670-687

Symmonds M, Emmanuel JJ, Drew ME, Batterham RL, Dolan RJ (2010) Metabolic state alters economic decision making under risk in humans. PLoS One 5(6):e11090

\section{Submit your manuscript to a SpringerOpen ${ }^{\circ}$} journal and benefit from:

- Convenient online submission

- Rigorous peer review

- Immediate publication on acceptance

- Open access: articles freely available online

- High visibility within the field

- Retaining the copyright to your article

Submit your next manuscript at $>$ springeropen.com 